\title{
Novel robot-assisted thyroidectomy by a transaxillary gas- insufflation approach (TAGA): a preliminary report
}

\author{
Chang Hwan Ryu", Jungirl Seok ${ }^{\# \wedge}$, Yuh-Seog Jung*, Junsun Ryu* \\ Department of Otorhinolaryngology-Head and Neck Surgery, National Cancer Center, Goyang, Republic of Korea \\ Contributions: (I) Conception and design: J Ryu, YS Jung; (II) Administrative support: J Ryu, YS Jung; (III) Provision of study materials or patients: \\ CH Ryu, J Ryu, YS Jung; (IV) Collection and assembly of data: CH Ryu; (V) Data analysis and interpretation: J Seok, CH Ryu; (VI) Manuscript \\ writing: All authors; (VII) Final approval of manuscript: All authors. \\ \#These authors contributed equally to this work as co-first authors. \\ *These authors contributed equally to this work as co-corresponding authors. \\ Correspondence to: Junsun Ryu, MD, PhD; Yuh-Seog Jung, MD, PhD. Department of Otorhinolaryngology-Head and Neck Surgery, National Cancer \\ Center, 323 Ilsan-ro, Ilsandong-gu, Goyang-si, Gyeonggi-do 410-769, Republic of Korea. Email: jsryu@ncc.re.kr; jysorl@ncc.re.kr.
}

\begin{abstract}
Background: Robot-assisted transaxillary approaches to thyroidectomy have been well described. They have an advantage over the breast approach in that a circumareolar incision is avoided. However, they require a single long axillary incision to accommodate all 3 robotic arms and provide adequate visualization of the area around the thyroid. The purpose of this study was to test the feasibility of the robot-assisted transaxillary gas-insufflation approach (TAGA) and to attempt reducing the size of the scar.

Methods: We evaluated 47 patients who underwent robot-assisted thyroid lobectomy via TAGA from July 2015 to Aug 2017. The following variables were studied: patients' demographics, operative time according to each operation step, volume of drainage, duration of hospitalization, and perioperative complications.

Results: The mean age of all patients was $42.4 \pm 9.1$ years. The mean total volume of drainage was $195.4 \pm 70.9 \mathrm{~mL}$, and the duration of postoperative stay was $3.0 \pm 1.1$ days. Two cases $(4.3 \%)$ of transient vocal cord palsy and 2 cases $(4.3 \%)$ of seroma were identified postoperatively. There was no post-operative cosmetic problem at the skin incisions made in the axilla.

Conclusions: Robot-assisted thyroid lobectomy via TAGA is technically feasible while achieving good cosmetic results. TAGA can be an alternative robot-assisted method for thyroidectomy.
\end{abstract}

Keywords: Thyroidectomy; remote access; robot-assisted; gas insufflation; transaxillary

Submitted Apr 09, 2020. Accepted for publication Sep 10, 2020.

doi: 10.21037/gs-20-450

View this article at: http://dx.doi.org/10.21037/gs-20-450

\section{Introduction}

The development of minimally invasive thyroidectomy is the result of the desires of surgeons to reduce pain and morbidity, shorten the period of hospitalization, and to improve the esthetic outcomes (1). Over the last decades, several techniques were developed for minimally invasive thyroid surgery that were especially focused on the cosmetic results (2). Since Yoon et al. described a gasless transaxillary approach (3), there have been improvements and modifications to their approach in order to reduce complications (4-9).

The transaxillary approach initially needed an additional incision on the anterior chest wall or breast, as well as in the axilla $(3,9-11)$. The additional incision leaves a scar that might be noticeable when a patient is wearing a sleeveless item of clothing or produces chronic numbness of the skin of the anterior chest. A robot-assisted thyroidectomy

\footnotetext{
$\wedge$ ORCID: 0000-0001-6473-6015.
} 
through a single axillary incision has also been described $(4,6)$; however, a long incision in the axilla was still required. In addition, a single-port traditional endoscopic transaxillary approach through smaller incisions has been reported $(7,12)$; but this approach is encumbered by the limitations of traditional endoscopic surgery, including difficulty of inverse controls, line-of-sight instrumentation, and collisions between the endoscopist and surgeon.

Herein, we report the preliminary results of a newly developed robot-assisted thyroidectomy procedure, namely, the transaxillary gas-insufflation approach (TAGA). This approach uses carbon dioxide gas $\left(\mathrm{CO}_{2}\right)$ instead of conventional mechanical retraction to obtain an adequate workspace, while maintaining the advantages of the transaxillary approach. Furthermore, instead of a single long incision, TAGA uses 3 small incisions consisting of three $10-\mathrm{mm}$ incisions, which should be a less invasive procedure and provide improved cosmetic outcomes. We present the following article in accordance with the STROBE reporting checklist (available at http://dx. doi. org/10. 21037/gs-20-450).

\section{Methods}

\section{Patients}

The medical records of 47 patients who underwent TAGA thyroidectomy and were diagnosed with papillary thyroid carcinoma from January 2016 to December 2017 at a single institution were retrospectively reviewed. The indications for TAGA thyroidectomy were as follows: thyroid nodules classified by a pathologist as a "suspicious follicular neoplasm" (Bethesda Category IV), "suspicious for malignancy" (Bethesda Category V), or "malignancy" (Bethesda Category VI). The contraindications for TAGA thyroidectomy were the need for total thyroidectomy and/ or elective central neck dissection, patient history of prior neck surgery or radiation, or underlying Graves' disease.

The patients' age at surgery (year), gender (number), operative time of each surgical step (minute), volume of drainage during the hospital stay $(\mathrm{mL})$, total number of days of hospitalization, complications during surgery and the follow-up period (number and rate), and pathology reports were reviewed. During the postoperative follow-up at the outpatient clinic, patients were asked if they were satisfied with the scar at the site of surgery.

The study was conducted in accordance with the Declaration of Helsinki (as revised in 2013). The study protocol was reviewed and approved by the institutional review board of the National Cancer Center, Korea. A waiver for informed consent was granted because of the retrospective design of the study (IRB No. NCC20190114).

\section{Surgical procedure}

Under general anesthesia, the patient was placed in the supine position with the neck extended by a pillow under the shoulder. The arm of the operated side was raised over the patient's head to expose the axilla; the other arm was in a natural position along the body. With the skin relaxed, the first $10-\mathrm{mm}$ incision was placed below the anterior axillary line along the skin crease of the axilla. Since the specimen will be removed through the first incision, the length of the incision can be up to $12 \mathrm{~mm}$, depending on the patient's skin elasticity and the size of the thyroid. The second 10 -mm incision was placed at the groove made by the upper lateral quadrant of the breast parenchyma and the anterior axillary line. The distance between the 2 incisions was about 8 to $9 \mathrm{~cm}$, to minimize interference between instruments. The last $10-\mathrm{mm}$ incision was placed between the first and second incisions (Figure 1A). All incision sites were used for 8-mm trocars (da Vinci Xi Bladeless Optical Obturator, Intuitive Surgical Inc., Sunnyvale, CA, USA).

An 8-mm trocar was then inserted into the suprafascial plane of the pectoralis major muscle through the uppermost incision (first incision). After $\mathrm{CO}_{2}$ gas was insufflated with a pressure of 5 to $8 \mathrm{mmHg}$, a rough suprafascial dissection using a vascular tunneler was carried out. Then, other trocars were inserted into the remaining 2 incisions. In this step, ensuring the intersection between the second trocar in the middle incision and the vascular tunneler in the uppermost incision was important, because it assured that all the trocars were in the same plane (Figure $1 B$ ). After insertion of a $0^{\circ}$ or $30^{\circ}$ endoscope through the axillary port (uppermost incision), a monopolar device and a dissector, which were inserted into the other ports, were used to continue the suprafascial dissection and create a working space. The working space was extended anteriorly to the sternal notch and posteriorly to $2-3 \mathrm{~cm}$ behind the sternocleidomastoid muscle (SCM). After the clavicle was identified, the robot was docked (Figure 1C).

The anatomical structures seen in the camera view are shown in Figure 2. The SCM muscle was exposed and placed below the dissection plane. The dissection was continued between the sternal head and clavicular head 
A

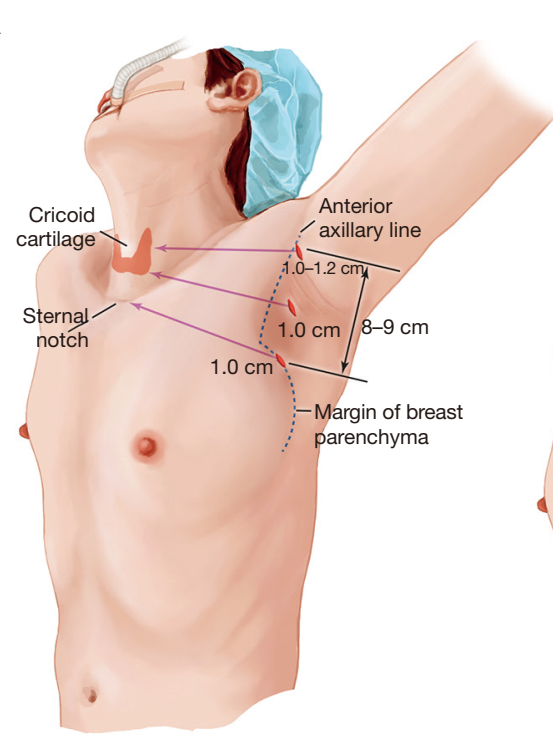

B

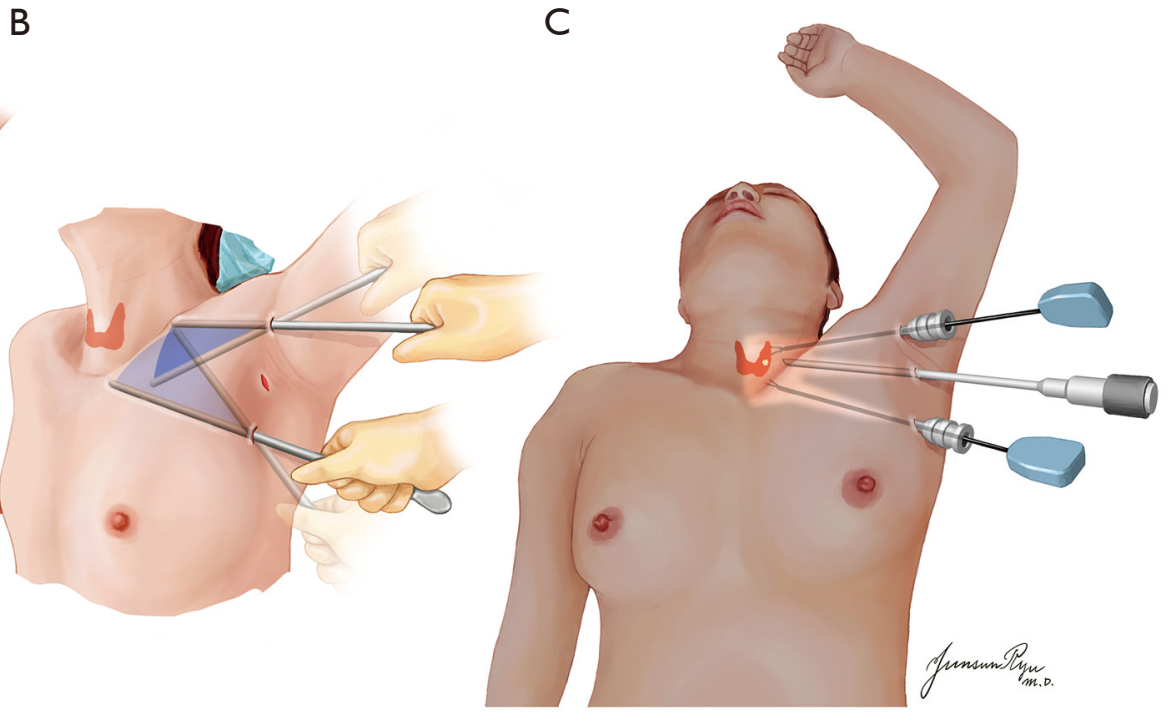

Figure 1 Schematic illustration of each stage of the surgical procedure. (A) Location and length of 3 incision sites, with at least a 4-cm distance between them. (B) Flap elevation using vascular tunneler. (C) Final position of instruments after docking.

of the SCM. The omohyoid muscle was cut if necessary. Further dissection identified the pulsating internal jugular vein (IJV) inferiorly on the display of the operative field. Once the IJV was secured onto the floor of the surgical plane, the dissection was continued under the sternothyroid muscle to expose the lateral side of the thyroid gland. It was important to assure that the dissection plane remained under the strap muscles. If the strap muscles or adjacent tissue sagged downward to interfere with the surgical field, additional sutures that applied traction to the strap muscles were needed to secure an adequate working space.

After the thyroid gland was exposed, the inferior pole of the thyroid gland and the trachea were exposed using the Maryland forceps and the harmonic scalpel. Then, the superior pole was carefully dissected, avoiding injury to the external branch of the superior laryngeal nerve and cricothyroid muscle. The capsular dissection of the thyroid by the harmonic scalpel was continued while grasping and elevating the thyroid medially to identify the recurrent laryngeal nerve (RLN) and inferior parathyroid gland. In this procedure, excessive traction of the thyroid was not required. A light lift of the thyroid can provide sufficient view of thyroid bed. After identification of the RLN, Berry's ligament was dissected with care to avoid injury to the RLN. The superior parathyroid gland was identified by this procedure. Finally, the isthmus was dissected.

A plastic bag was inserted through the trocar within the first incision; the resected thyroid lobe was collected and placed in the bag and pulled up to the opening of the trocar. The plastic bag enveloping the specimen was retrieved together with the axillary trocar. This procedure allowed the trocar to act as a stent, enabling the thyroid specimen to exit the tract safely. If the incision for the first trocar insertion site was initially $10 \mathrm{~mm}$ at the time of incision, the specimen can be retrieved more easily by increasing the incision by $2 \mathrm{~mm}$. After removal of the specimen, a suction drain was inserted through the incision site. The subcutaneous tissue and skin were sutured, and a surgical brassiere was applied (Figure 3).

\section{Statistical analysis}

Statistical analysis was performed using R Statistical Software (version 3.6.0; R Foundation for Statistical Computing, Vienna, Austria). The change in the operation time according to the number of operation cases was obtained through linear regression, the level of statistical significance was set at a $\mathrm{P}$ value of $<0.05$.

\section{Results}

A total of 47 patients underwent thyroid lobectomy by TAGA. Their demographic data and clinical results are shown in Table 1. All patients were female and underwent 

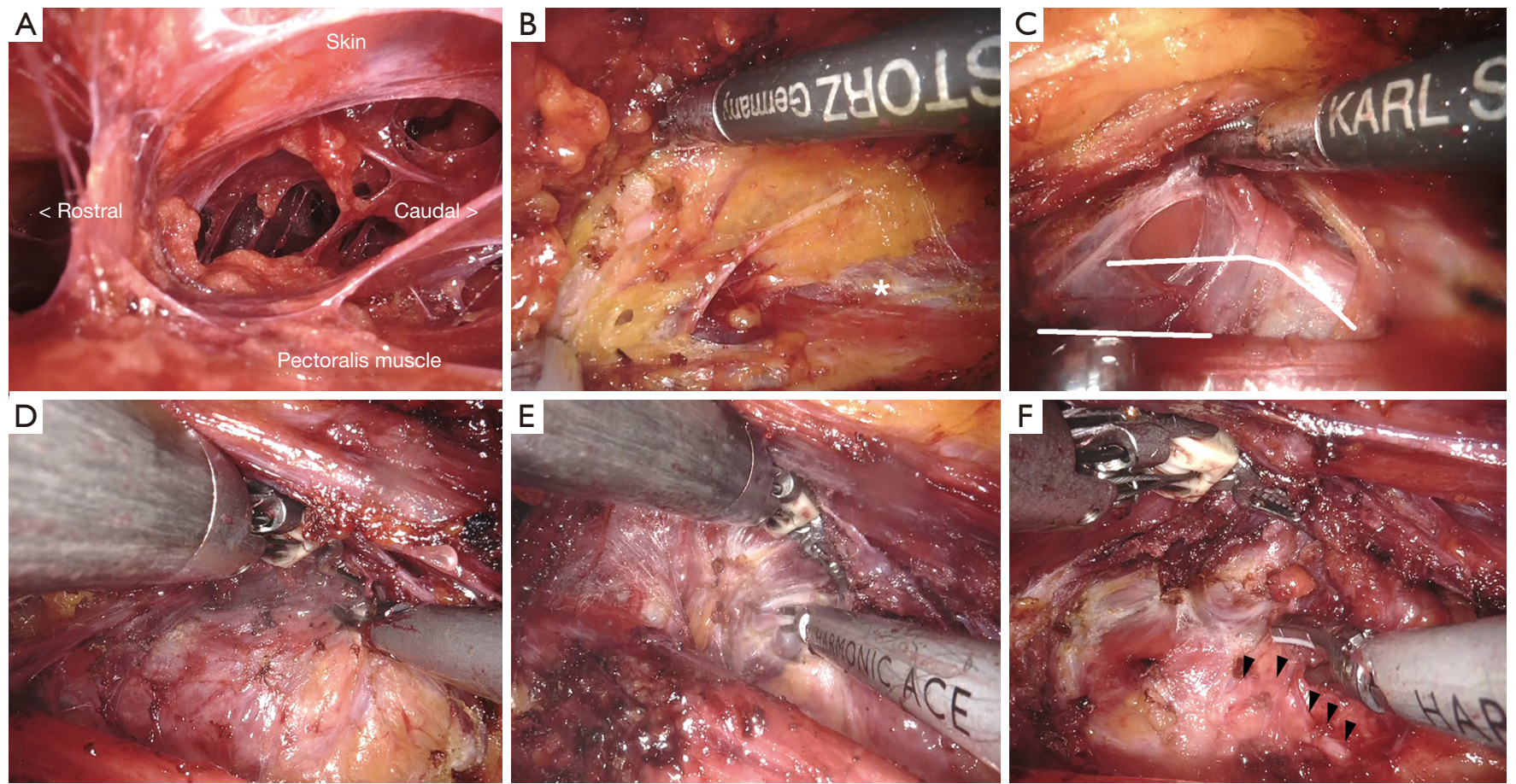

Figure 2 The anatomical structures seen in the camera views. The photographs obtained from a right-sided transaxillary gas-insufflation approach (TAGA). All photographs were taken with a 0-degree camera. (A) Working space immediately after flap elevation by the vascular tunneler. The soft tissues between the flap and pectoralis major muscle are to be dissected. (B) Dissection plane is the fissure between the sternal and clavicular heads of the sternocleidomastoid muscle (SCM) (white asterisk). (C) After elevation of the omohyoid muscle by an instrument, the purplish internal jugular vein (IJV) (white lines) can be seen under the omohyoid muscle. To avoid damage, IJV is needed be separated from the omohyoid muscle. (D) Exposure of the thyroid gland. The skin flap and strap muscles are placed superiorly, and the IJV (not shown) and clavicular head of the SCM are placed inferiorly to the thyroid gland. (E) The vasculature of the upper pole of the right thyroid lobe is ligated. (F) The thyroid lobe is pulled upward to expose recurrent laryngeal nerve (black arrowheads). The thyroid lobe needs to be lifted medially, but excessive traction is not required.
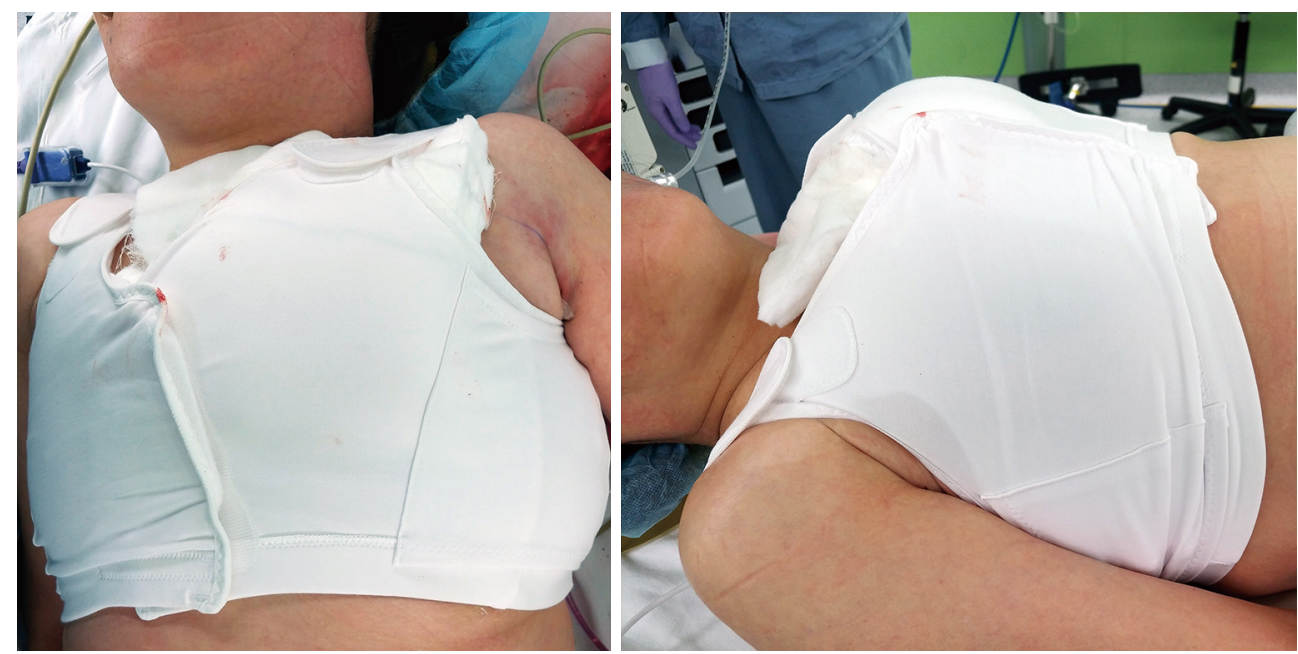

Figure 3 Photographs of patient wearing surgical brassiere immediately after a left-sided transaxillary gas-insufflation approach (TAGA). The skin flap that was elevated during procedure was effectively compressed by placing gauze between the skin and the brassiere. 
Table 1 Demographics and clinical characteristics of the study population

\begin{tabular}{|c|c|}
\hline Variables & Value \\
\hline No. of patients & 47 \\
\hline Age (years), mean \pm SD [range] & $42.4 \pm 9.1[19-59]$ \\
\hline Male/female & $0 / 47$ \\
\hline \multicolumn{2}{|c|}{ Pathologic TNM stage (AJCC 2010), n (\%) } \\
\hline Stage I & $35(74.5)$ \\
\hline Stage III & $9(19.1)$ \\
\hline Benign & $3(6.4)$ \\
\hline \multicolumn{2}{|l|}{ Type of surgery, n (\%) } \\
\hline Left lobectomy & $20(42.6)$ \\
\hline Right lobectomy & $27(57.4)$ \\
\hline Drainage volume $(\mathrm{mL})$, mean $\pm \mathrm{SD}$ & $195.4 \pm 70.9$ \\
\hline $\begin{array}{l}\text { Duration of postoperative stay (days), } \\
\text { mean } \pm S D\end{array}$ & $3.0 \pm 1.1$ \\
\hline \multicolumn{2}{|l|}{ Operative time (minutes), mean $\pm S D$} \\
\hline Total & $153.9 \pm 53.1$ \\
\hline Draping time, range & $5-10$ \\
\hline Flap elevation time & $47.5 \pm 24.0$ \\
\hline Docking time & $8.1 \pm 4.0$ \\
\hline Console time & $54.3 \pm 28.4$ \\
\hline Closure time & $39.3 \pm 22.9$ \\
\hline \multicolumn{2}{|l|}{ Thyroid lobe specimen, mean \pm SD [range] } \\
\hline Longest diameter $(\mathrm{cm})$ & $4.4 \pm 0.6[3.0-6.0]$ \\
\hline Axial cross-sectional area $\left(\mathrm{cm}^{2}\right)^{*}$ & $2.6 \pm 1.1[0.4-5.3]$ \\
\hline Weight $(g)$, mean \pm SD & $11.0 \pm 3.2$ \\
\hline
\end{tabular}

*, the ellipse formula was used. TNM, tumor $(\mathrm{T})$, nodes $(\mathrm{N})$ and metastases (M); AJCC, American Joint Committee on Cancer; SD, standard deviation.

Table 2 Postoperative complications of the 47 patients

\begin{tabular}{lc}
\hline Complications & $\mathrm{N}(\%)$ \\
\hline Temporary vocal cord paralysis & $2(4.3)$ \\
Permanent vocal cord paralysis & 0 \\
Seroma & $2(4.3)$ \\
Hematoma & 0 \\
Infection & 0 \\
Keloid/hypertrophic scar & 0 \\
\hline
\end{tabular}

lobectomy. Including the benign lesions, all tumors measured less than $4 \mathrm{~cm}$. Since central node dissection was not an indication for TAGA, all patients with papillary thyroid carcinoma had stage I or II disease (stage I: 74.5\%, stage II: $19.1 \%$, benign: $6.4 \%$ ). The maximum diameter of thyroid specimens was $6.0 \mathrm{~cm}$ (mean $4.4 \pm 0.6 \mathrm{~cm}$ ). The mean maximum elliptical axial cross-sectional area was $2.6 \pm 1.1 \mathrm{~cm}^{2}$ (range, 0.4 to $5.3 \mathrm{~cm}^{2}$ ).

The postoperative complications are shown in Table 2. In all 47 patients, the RLN was identified and preserved during the thyroid lobectomy by TAGA. Two patients $(4.3 \%)$ developed temporary vocal cord paralysis and recovered within 3 months. Permanent vocal cord paralysis did not occur. Postoperative hematoma with subsequent reoperation did not occur. Two cases of seroma occurred and were treated and resolved by aspiration at the outpatient clinic. All patients were satisfied with their cosmetic outcomes; skin problems, including keloids and hypertrophic scars, did not occur (Figure 4).

The mean operative times for the first 23 cases and the second 24 cases were $172 \pm 62$ and $137 \pm 36$ minutes, respectively ( $\mathrm{P}=0.023$, Student's $t$-test). The detailed results are shown in Figure 5. The total operative time tended to decrease over time, but the decrease was not significant $(-1.09$ minute per case, $\mathrm{P}=0.055)$. When each operative surgical step was evaluated, the time for flap elevation was found to be significantly decreased $(-0.52$ minute per case, $\mathrm{P}=0.044)$. The times for docking, console, and closure did not change significantly.

The 24-hour drainage volume of each patient was checked at 6:00 AM every day, and when the volume of daily drainage measured $<30 \mathrm{~mL}$, the drain was removed, and the patient was discharged. The durations of postoperative stays and total volumes of drainage decreased slightly with experience, but the changes were not significant $(-0.02$ day per case, $\mathrm{P}=0.115,-0.54 \mathrm{~mL}$ per case, $\mathrm{P}=0.486$ ).

\section{Discussion}

Since the early 2000s, various minimally invasive procedures have been developed for thyroidectomy $(1,13)$. Each surgical procedure was chosen according to the equipment of the institution and preferences of the surgeons. Endoscopicguided transaxillary thyroidectomy was introduced in 2009 $(3,14)$, and descriptions of the various methods used by this approach, including robot-assisted manipulations, have been published $(6-8,15,16)$. 

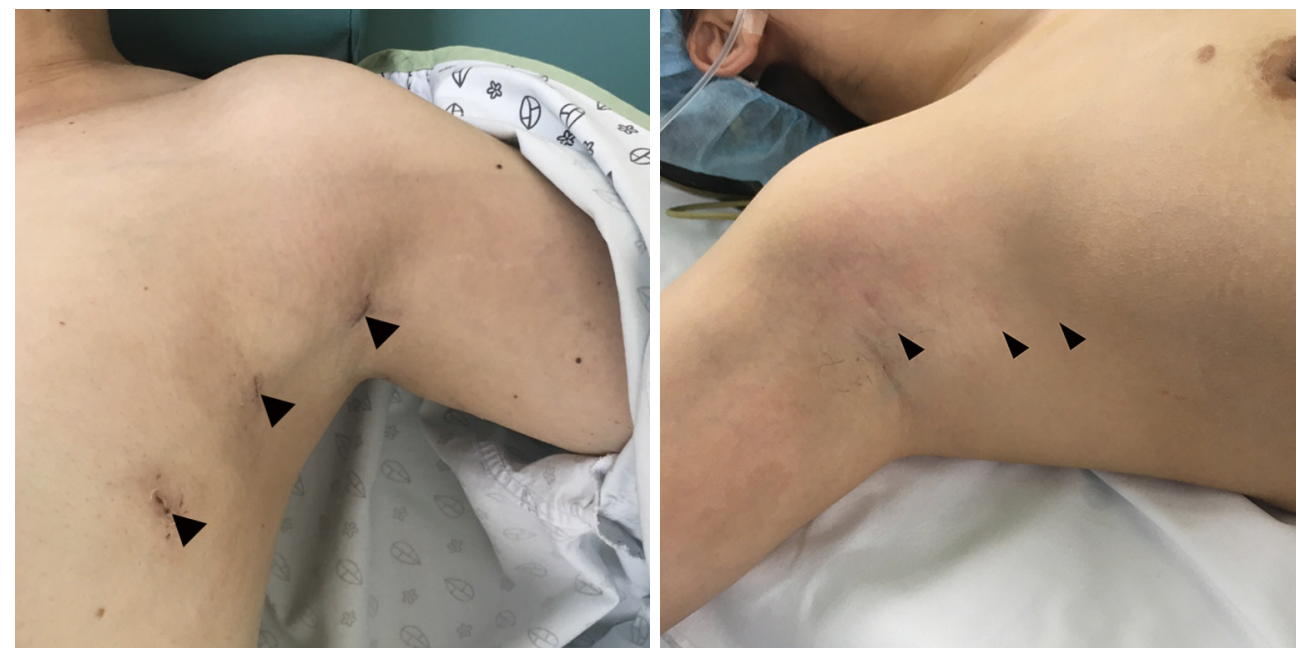

Figure 4 Photographs of the incision sites of two patients, at 2 weeks (left) and 1 year (right) after surgery. Crusting involved 3 incision sites at 2 weeks after surgery. After a year, the sites were almost invisible. Note that black arrows in both images indicate the 3 incision sites.

There are 2 general types of approaches. One type of approach has not used gas insufflation, and instead uses a single long axillary incision. Prete $e t$ al. reported on their series of patients undergoing a transaxillary robot-assisted thyroidectomy based on the da Vinci Xi platform. That procedure could be performed with an incision that was at least $6 \mathrm{~cm}$ in length (16).

The other type of approach has used gas insufflation, which produces a smaller scar and avoids excessive mechanical retraction by conventional retractors. However, with gas insufflation, additional incisions are required for the robotic arms, and there are procedures that require a circumareolar incision $(9,17,18)$.

Basically, each general type of procedure has advantages and disadvantages (19). The TAGA is a modification of the existing remote access procedures. Lee et al. has introduced a unilateral axillo-breast approach (UABA) that uses gas insufflation (9). This method can overcome the limitations of the transaxillary approach without gas insufflation, including a long axillary incision and prolonged, extensive muscle retraction. Therefore, it does not require a large axillary flap and reduces postoperative pain and drainage volume. An important feature of UABA with gas insufflation is that it is a 3-port, robot-assisted procedure. Before the introduction of this 3-port, robot-assisted procedure, Ikeda et al. and Ohgami et al. had found that endoscopic-guided thyroidectomy using a 3 -port system was possible $(20,21)$. TAGA has features of the 3 -port system and gas insufflation, providing small scars and good visibility because of gas insufflation. Without involving an incision around the areola, this approach follows a pathway similar to that of the endoscopic thyroidectomy procedure introduced by Ikeda et al. (20) However, the major difference between their approach and ours is that they performed a $30-\mathrm{mm}$ incision and dissected the lower layer of the platysma muscle, and then 12 - and $5-\mathrm{mm}$ trocars were inserted. A purse-string suture was needed between the 2 trocars to retain the gas and prevent the trocars from slipping out of the wound. Instead, we made three $10-\mathrm{mm}$ incisions, and successfully elevated a subplatysmal flap by a tunneler. Although not a big difference, the scars from short incisions are less visible than the scar from a single long incision.

Regardless of gas insufflation, successful thyroidectomy has been performed by endoscopic thyroidectomy via a single port $(12,22)$. The da Vinci SP system (Intuitive Surgical Inc., Goleta, CA, USA) was recently introduced for robot-assisted thyroidectomy; however, it seems difficult to replace the current robot-assisted surgery systems immediately. Furthermore, the diameter of the single arm of the da Vinci SP system is $2.5 \mathrm{~cm}$, which requires a larger incision than the incision needed by TAGA.

We presumed that a circumareolar incision would not be necessary to provide an adequate surgical field for a thyroid lobectomy not requiring a central node dissection. Previous studies have found recovery of sensation by the nipple and chest to the level before surgery $(18,23,24)$. However, hyperesthesia can occur in the individual patient when the complicated innervation of the nipple-areolar complex is 


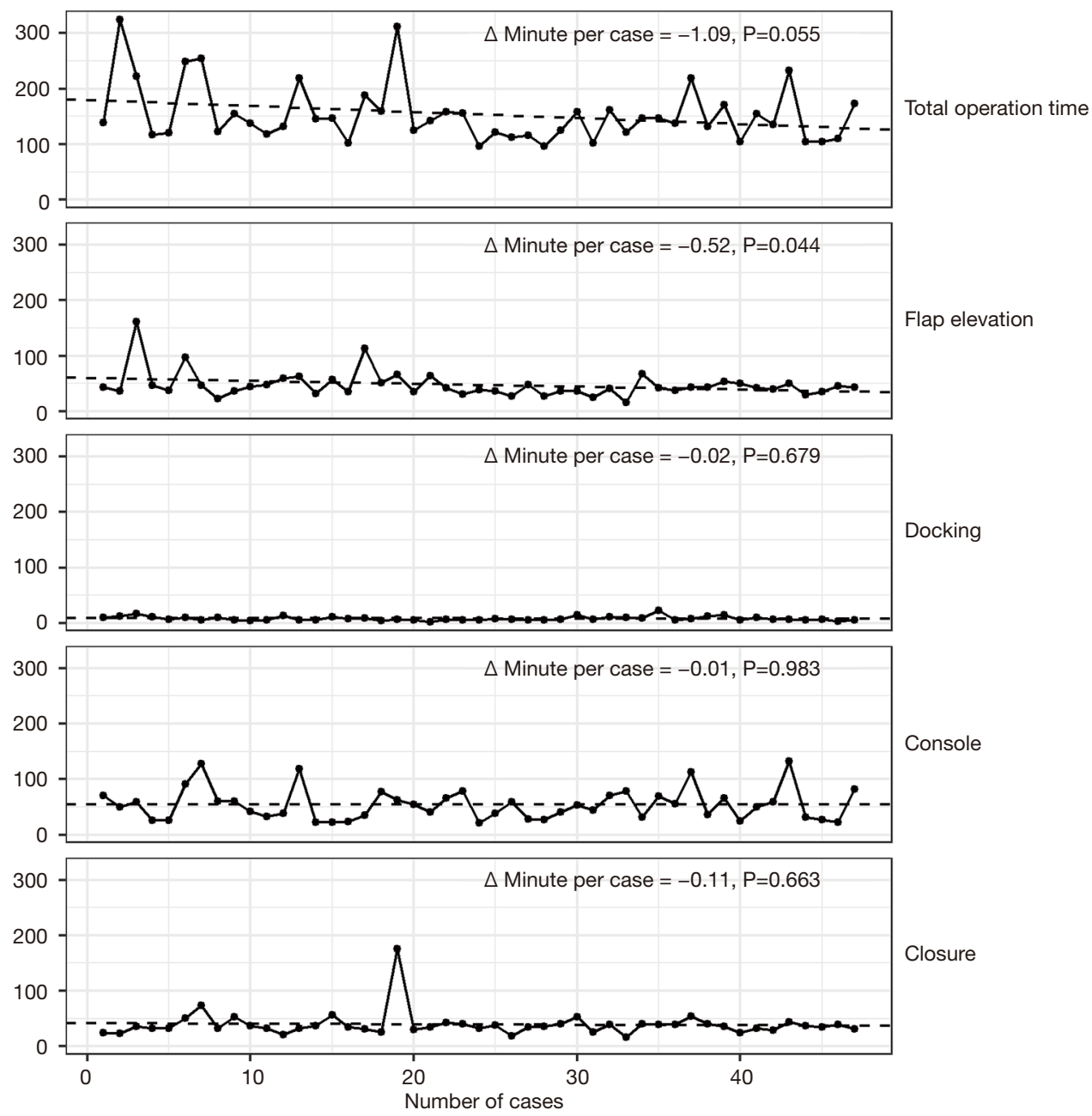

Figure 5 Changes in total operative time and the time required by each step of the operation according to the number of cases performed.

taken into consideration (25). This could lead to extreme discomfort with painful sensations and adversely affect the patient's quality of life. Therefore, we developed our 3-port approach via the axilla to avoid an unnecessary incision on the breast. Three small midaxillary incisions were made for this purpose, with a total incision length not exceeding $32 \mathrm{~mm}$. The total length of the scars is shorter than those occurring after the currently available approaches used in robot-assisted thyroidectomy, with the exception of the transoral approach. At 1 year after surgery, the incision lines were mostly invisible. Cosmetically important keloid or hypertrophic scars did not occur.

In our study, the mean operative time was $153.9 \pm 53.1$ minutes, which was longer than that the previously reported times of other robot-assisted transaxillary approaches
$(5,6,11,26)$. Considering that our study provides preliminary results from our new approach, our total operative time might be a reflection of our learning curve. The major reason accounting for the increased time for TAGA is that the approach uses a 2 -arm system and a narrower working space than the space provided by other robot-assisted approaches, where 1 more arm can be utilized, and is thus technically demanding for beginners.

However, as we examined each case, we did not find a definite learning curve, but saw a gradual improvement in the operative time. The difference between the mean operative times of the first 23 cases and the second 24 cases was significant $(172 \pm 62$ and $137 \pm 36$ minutes, respectively; $\mathrm{P}=0.023)$. Among the surgical steps, the flap elevation times were significantly decreased linearly over time $(-0.52$ minute 
per case, $\mathrm{P}=0.044)$. The console times, which are devoted to the use of the robot, remained almost unchanged $(\mathrm{P}=0.983)$, because the physicians performing the surgery $(\mathrm{CH}$ Ryu, YS Jung, J Ryu) were probably experienced in performing robot-assisted transaxillary endoscopic thyroidectomy and UABA before they developed this current approach.

The mean duration of postoperative stay of the study patients was $3.0 \pm 1.1$ days, which is similar to the stays reported by previous studies using a robot. Kang et al. reported that the mean postoperative hospital stay of the patients undergoing their robot-assisted transaxillary endoscopic thyroidectomy was $3.2 \pm 0$.6 days (5). In a large series of 3,000 patients undergoing robotic thyroidectomy, the mean postoperative hospital stay was $3.26 \pm 1.72$ days (11).

Although this preliminary study did not include a comparison group, the clinical outcome was not inferior to previously reported studies. Reviews by Liu et al. and Lang et al., which compared robotic versus nonrobotic thyroidectomies, reported temporary and permanent RLN injury rates ranging from $1 \%$ to $7 \%$ for temporary and $0 \%$ to $2 \%$ for permanent injury. The rate of temporary RLN injury was significantly higher in robotic than in nonrobotic thyroidectomies $(27,28)$. In our study, two patients received transient injury to the RLN, which resolved within 6 months. None of the patients received a permanent RLN injury. Furthermore, hematomas were not observed, and the two seromas that developed resolved after aspiration at our clinic without complications. And last, there was no risk of pneumomediastinum because the patient needed central node dissection was not indication of this procedure. However, the interpretation of our results is limited, because this study included a small number of patients without a comparison group.

An analysis of the indications and contraindications of TAGA was not the focus of this preliminary study; however, Tae et al. have postulated that metastasis to the lymph nodes of the central or lateral compartments can be an indication for robotic thyroidectomy (29). For our approach, however, the narrow working space and the 2-arm system led to difficulty in performing a thyroidectomy on the contralateral side and dissection of the central lymph nodes of the neck. However, the need for central neck node dissection in total thyroidectomy remains controversial (30-34); therefore, if a carefully selected patient has indications for lobectomy only, a lobectomy without central neck node dissection can be performed safely while allowing the best cosmetic result.
Gas insufflation has been reported to be associated with various complications, including subcutaneous emphysema, pneumomediastinum, increased $\mathrm{PaCO}_{2}$, and severe tachycardia $(29,35)$. However, studies have reported that appropriate pressures of $\mathrm{CO}_{2}$ do not result in adverse physiological reactions $(20,36,37)$. Low insufflation pressures have also been reported to prevent gas emboli (38). However, some studies have reported that $\mathrm{CO}_{2}$ emboli have occurred in patients undergoing thyroidectomy with gas insufflation (39-41). According to Park et al., laceration of the anterior jugular vein during flap elevation has led to $\mathrm{CO}_{2}$ embolism (41). With TAGA, the injured anterior, internal, and/or external jugular veins can be an inlet for embolism during surgery. To avoid large vessel injuries, the dissection between the bifurcation of the SCM muscle and identification of the IJV are particularly important. If the dissection was carried on posterior border of the SCM, external jugular vein may be at risk of being injured. If the dissection is carried out on anterior border of the SCM, the anterior jugular vein can be injured. In order to identify the bifurcation of the SCM muscle, a preoperative CT might be helpful in verifying the location where the 2 heads of the SCM muscle divide. Even without CT, since the origin of the sternal head of SCM is the manubrium, which is observed at the medial side of the sternal notch, so the location where the two heads of the SCM divide can be confirmed without difficulty when dissecting toward the sternal notch.

In addition, the $\mathrm{CO}_{2}$ insufflation pressures of TAGA ranged from 5 to $8 \mathrm{mmHg}$, which are the same range of pressures used for UABA or bilateral axillo-breast approach (UABA) $(9,42)$, but are higher than the pressures used by Ikeda et al. (20). However, we did not observe instability of the patients' vital signs during general anesthesia; and hypercapnia, respiratory acidosis, subcutaneous emphysema, and $\mathrm{CO}_{2}$ emboli did not occur.

This study is limited because it is a preliminary report of a study of a surgical approach that has not been prospectively compared with other surgical approaches. Accordingly, patient satisfaction regarding their scars could not be objectively quantified. Prospective studies are needed on the complications, operative time, and patient satisfaction regarding pain, as well as oncologic outcomes of thyroid lobectomy via a robot-assisted TAGA.

\section{Conclusions}

We developed and successfully performed thyroid 
lobectomies by a robot-assisted TAGA. Gas insufflation was found to minimize mechanical retraction, adverse reactions and perioperative problems. The major advantages of TAGA are the resulting 3 barely visible, small scars and the minimal damage to subcutaneous breast tissue without interrupting the routine surgical procedures for transaxillary thyroidectomy.

\section{Acknowledgments}

Funding: None.

\section{Footnote}

Reporting Checklist: The authors have completed the STROBE reporting checklist. Available at http://dx.doi. org/10.21037/gs-20-450

Data Sharing Statement: Available at http://dx. doi. org/10. 21037/gs-20-450

Conflicts of Interest: All authors have completed the ICMJE uniform disclosure form (available at http://dx. doi. org/10. 21037/gs-20-450). The authors have no conflicts of interest to declare.

Ethical Statement: The authors are accountable for all aspects of the work in ensuring that questions related to the accuracy or integrity of any part of the work are appropriately investigated and resolved. The study was conducted in accordance with the Declaration of Helsinki (as revised in 2013). The study protocol was reviewed and approved by the institutional review board of the National Cancer Center, Korea. A waiver for informed consent was granted because of the retrospective design of the study (IRB No. NCC2019-0114).

Open Access Statement: This is an Open Access article distributed in accordance with the Creative Commons Attribution-NonCommercial-NoDerivs 4.0 International License (CC BY-NC-ND 4.0), which permits the noncommercial replication and distribution of the article with the strict proviso that no changes or edits are made and the original work is properly cited (including links to both the formal publication through the relevant DOI and the license). See: https://creativecommons.org/licenses/by-ncnd/4.0/.

\section{References}

1. Linos D. Minimally invasive thyroidectomy: a comprehensive appraisal of existing techniques. Surgery 2011;150:17-24.

2. Miyano G, Lobe TE, Wright SK. Bilateral transaxillary endoscopic total thyroidectomy. J Pediatr Surg 2008;43:299-303.

3. Yoon JH, Park CH, Chung WY. Gasless endoscopic thyroidectomy via an axillary approach: experience of 30 cases. Surg Laparosc Endosc Percutan Tech 2006;16:226-31.

4. Nam KH, Owen R, Inabnet III WB. Prevention of complications in transaxillary single-incision robotic thyroidectomy. Thyroid 2012;22:1266-74.

5. Kang SW, Jeong JJ, Nam KH, et al. Robot-assisted endoscopic thyroidectomy for thyroid malignancies using a gasless transaxillary approach. J Am Coll Surg 2009;209:e1-e7.

6. Ryu HR, Kang SW, Lee SH, et al. Feasibility and safety of a new robotic thyroidectomy through a gasless, transaxillary single-incision approach. J Am Coll Surg 2010;211:e13-9.

7. Fan Y, Wu SD, Kong J. Single-port access transaxillary totally endoscopic thyroidectomy: a new approach for minimally invasive thyroid operation. J Laparoendosc Adv Surg Tech A 2011;21:243-7.

8. Lee D, Nam Y, Sung K. Single-incision endoscopic thyroidectomy by the axillary approach. J Laparoendosc Adv Surg Tech A 2010;20:839-42.

9. Lee MC, Mo JA, Choi IJ, et al. New endoscopic thyroidectomy via a unilateral axillo-breast approach with gas insufflation: Preliminary report. Head Neck 2013;35:471-6.

10. Lewis CM, Chung WY, Holsinger FC. Feasibility and surgical approach of transaxillary robotic thyroidectomy without CO2 insufflation. Head Neck 2010;32:121-6.

11. Ban EJ, Yoo JY, Kim WW, et al. Surgical complications after robotic thyroidectomy for thyroid carcinoma: a single center experience with 3,000 patients. Surg Endosc 2014;28:2555-63.

12. Cho J, Lee D, Baek J, et al. Single-incision endoscopic thyroidectomy by the axillary approach with gas inflation for the benign thyroid tumor: retrospective analysis for a single surgeon's experience. Surg Endosc 2017;31:437-44.

13. Materazzi G, Fregoli L, Manzini G, et al. Cosmetic result and overall satisfaction after minimally invasive video- 
assisted thyroidectomy (MIVAT) versus robot-assisted transaxillary thyroidectomy (RATT): a prospective randomized study. World J Surg 2014;38:1282-8.

14. Kang SW, Jeong JJ, Yun JS, et al. Gasless endoscopic thyroidectomy using trans-axillary approach; surgical outcome of 581 patients. Endocr J 2009;56:361-9.

15. Kang SW, Lee SC, Lee SH, et al. Robotic thyroid surgery using a gasless, transaxillary approach and the da Vinci S system: the operative outcomes of 338 consecutive patients. Surgery 2009;146:1048-55.

16. Prete FP, Marzaioli R, Lattarulo S, et al. Transaxillary robotic-assisted thyroid surgery: technique and results of a preliminary experience on the Da Vinci Xi platform. BMC Surg 2019;18:19.

17. Nayak SP, Sadhoo A, Gangadhara B, et al. Roboticassisted breast-axillo insufflation thyroidectomy (RABIT): a retrospective case series of thyroid carcinoma. Int J Clin Oncol 2020;25:439-45.

18. Kim SJ, Lee KE, Myong JP, et al. Prospective study of sensation in anterior chest areas before and after a bilateral axillo-breast approach for endoscopic/robotic thyroid surgery. World J Surg 2013;37:1147-53.

19. Muenscher A, Dalchow C, Kutta H, et al. The endoscopic approach to the neck: a review of the literature, and overview of the various techniques. Surg Endosc 2011;25:1358-63.

20. Ikeda Y, Takami H, Niimi M, et al. Endoscopic thyroidectomy and parathyroidectomy by the axillary approach. Surg Endosc 2002;16:92-5.

21. Ohgami M, Ishii S, Arisawa Y, et al. Scarless endoscopic thyroidectomy: breast approach for better cosmesis. Surg Laparosc Endosc Percutan Tech 2000;10:1-4.

22. Zhu G, Zhang M, Zhang X, et al. Transareola single-site laparoendoscopic bilateral thyroidectomy. J Laparoendosc Adv Surg Tech A 2014;24:379-82.

23. Song CM, Ji YB, Bang HS, et al. Long-term sensory disturbance and discomfort after robotic thyroidectomy. World J Surg 2014;38:1743-8.

24. Kim SJ, Lee KE, Myong JP, et al. Recovery of sensation in the anterior chest area after bilateral axillo-breast approach endoscopic/robotic thyroidectomy. Surg Laparosc Endosc Percutan Tech 2011;21:366-71.

25. Jaspars JJ, Posma AN, Van Immerseel AA, et al. The cutaneous innervation of the female breast and nippleareola complex: implications for surgery. Br J Plast Surg 1997;50:249-59.

26. Kandil EH, Noureldine SI, Yao L, et al. Robotic transaxillary thyroidectomy: an examination of the first one hundred cases. J Am Coll Surg 2012;214:558-64.

27. Liu SY, Ng EK. Robotic versus Open Thyroidectomy for Differentiated Thyroid Cancer: An Evidence-Based Review. Int J Endocrinol 2016;2016:4309087.

28. Lang BH, Wong CK, Tsang JS, et al. A systematic review and meta-analysis comparing outcomes between roboticassisted thyroidectomy and non-robotic endoscopic thyroidectomy. J Surg Res 2014;191:389-98.

29. Tae K, Ji YB, Song CM, et al. Robotic and endoscopic thyroid surgery: evolution and advances. Clin Exp Otorhinolaryngol 2019;12:1-11.

30. Zetoune T, Keutgen X, Buitrago D, et al. Prophylactic central neck dissection and local recurrence in papillary thyroid cancer: a meta-analysis. Ann Surg Oncol 2010;17:3287-93.

31. Wang TS, Cheung K, Farrokhyar F, et al. A metaanalysis of the effect of prophylactic central compartment neck dissection on locoregional recurrence rates in patients with papillary thyroid cancer. Ann Surg Oncol 2013;20:3477-83.

32. Matsuzu K, Sugino K, Masudo K, et al. Thyroid lobectomy for papillary thyroid cancer: long-term followup study of 1,088 cases. World J Surg 2014;38:68-79.

33. Macedo FIB, Mittal VK. Total thyroidectomy versus lobectomy as initial operation for small unilateral papillary thyroid carcinoma: a meta-analysis. Surg Oncol 2015;24:117-22.

34. Lee J, Park JH, Lee CR, et al. Long-term outcomes of total thyroidectomy versus thyroid lobectomy for papillary thyroid microcarcinoma: comparative analysis after propensity score matching. Thyroid 2013;23:1408-15.

35. Kandil E, Hammad AY, Walvekar RR, et al. Robotic thyroidectomy versus nonrobotic approaches: a metaanalysis examining surgical outcomes. Surg Innov 2016;23:317-25.

36. Kim JA, Kim JS, Chang MS, et al. Influence of carbon dioxide insufflation of the neck on intraocular pressure during robot-assisted endoscopic thyroidectomy: a comparison with open thyroidectomy. Surg Endosc 2013;27:1587-93.

37. Ochiai R, Takeda J, Noguchi J, et al. Subcutaneous carbon dioxide insufflation does not cause hypercarbia during endoscopic thyroidectomy. Anesth Analg 2000;90:760-2.

38. Anuwong A, Sasanakietkul T, Jitpratoom P, et al. Transoral endoscopic thyroidectomy vestibular approach (TOETVA): indications, techniques and results. Surg Endosc 2018;32:456-65.

39. Kim KN, Lee DW, Kim JY, et al. Carbon dioxide 
embolism during transoral robotic thyroidectomy: a case report. Head Neck 2018;40:E25-8.

40. Fu J, Luo Y, Chen Q, et al. Transoral endoscopic thyroidectomy: review of 81 cases in a single institute. $\mathrm{J}$ Laparoendosc Adv Surg Tech A 2018;28:286-91.

41. Park JO, Anuwong A, Kim MR, et al. Transoral endoscopic thyroid surgery in a Korean population. Surg Endosc 2019;33:2104-13.

42. Kim HY, Choi YJ, Yu HN, et al. Optimal carbon dioxide insufflation pressure during robot-assisted thyroidectomy in patients with various benign and malignant thyroid diseases. World J Surg Oncol 2012;10:202.
Cite this article as: Ryu CH, Seok J, Jung YS, Ryu J. Novel robot-assisted thyroidectomy by a transaxillary gas-insufflation approach (TAGA): a preliminary report. Gland Surg 2020;9(5):1267-1277. doi: 10.21037/gs-20-450 